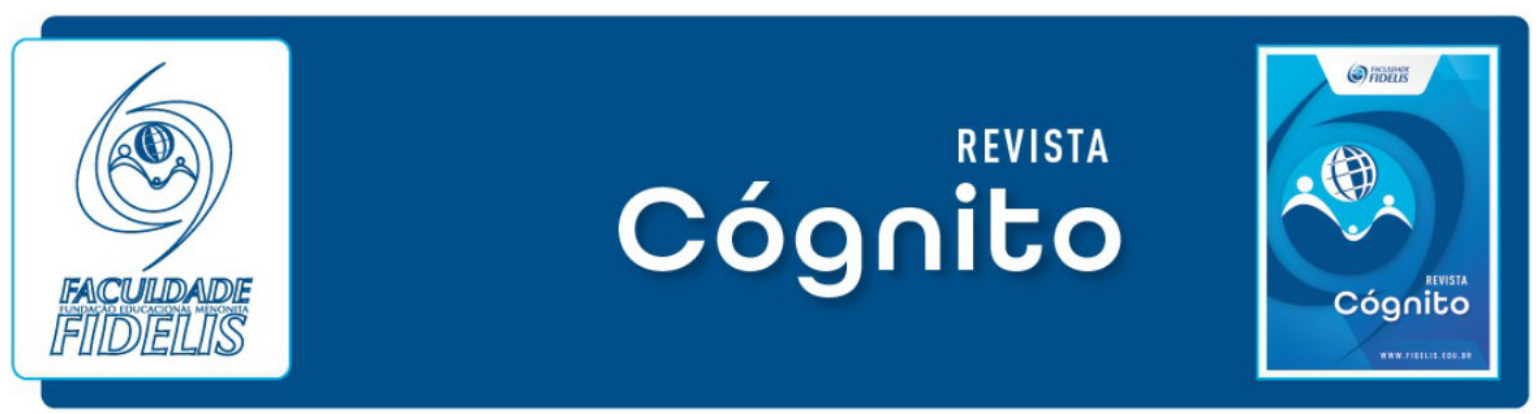

\title{
A SAÚDE EMOCIONAL DO MISSIONÁRIO E A RESPONSABILIDADE DA IGREJA
}

\section{THE EMOTIONAL HEALTH OF THE MISSIONARY AND THE RESPONSIBILITY OF THE CHURCH}

\section{Christian Abram Friesen ${ }^{1}$ Mariluce Emerim de Melo August ${ }^{2}$}

\section{RESUMO}

Este estudo trata sobre a realidade e necessidade de cuidado dos missionários em relação a sua saúde emocional, e da responsabilidade da igreja para com o cuidado integral da pessoa do missionário. Tem como objetivo alertar pastores, líderes e os próprios missionários quanto aos desafios, muitas vezes, enfrentados no campo missionário, que não envolvem recursos financeiros, mas sim, necessidade de um cuidado pastoral e espiritual. Pela pesquisa bibliográfica foi identificada a carência de diálogo sobre a saúde emocional de missionários entre eles e líderes religiosos no âmbito da igreja. Tanto o missionário, como a igreja precisam ser melhor preparados para lidar com este assunto.

Palavras-chave: Saúde emocional. Cuidado integral. Missionário super-herói. Missionário mártir. Sofrimento do missionário.

\begin{abstract}
This work addresses the reality and need for missionary care in relation to their emotional health, and the responsibility of the church for the integral care of the missionary. It aims to alert pastors, leaders and the missionaries themselves about the challenges often faced in the mission field, which do not involve financial resources, but rather the need of pastoral and spiritual care.
\end{abstract}

${ }^{1}$ Discente do curso de Bacharelado em Teologia da Faculdade Fidelis.

${ }^{2}$ Doutora em Teologia pela PUCPR. Docente do curso de Bacharelado em Teologia da Faculdade. Fidelis. e-mail: mariluce.august@fidelis.edu.br 
Bibliographical research was used to identify the lack of dialogue about the emotional health of missionaries and religious leaders within the church. Both, the missionary and the church, need to be better prepared to deal with this matter.

Keywords: Emotional Health. Integral Care. Superhero Missionary. Martyr Missionary. Missionary Suffering.

\section{INTRODUÇÃO}

Atualmente, em países cristãos, existem centenas de agências missionárias de confissão evangélica que treinam e enviam missionários com o objetivo de levarem a mensagem redentora de Cristo a todas as nações. Estes missionários são pessoas que se sentem chamadas para irem até os confins da Terra. São impulsionados, muitas vezes, pelos versículos bíblicos que envolvem a grande comissão, como as palavras de Jesus no texto do evangelho de Mateus 28.19², "ide, portanto, fazei discípulos de todas as nações, batizando-os em nome do Pai, e do Filho, e do Espírito Santo", e no de Marcos 16.15, "ide por todo o mundo e pregai o evangelho a toda criatura." Ou, são inspirados, ainda, pelo texto que fala do chamado de Isaías 6.8, "depois disto, ouvi a voz do Senhor, que dizia: A quem enviarei, e quem há de ir por nós? Disse eu: eis-me aqui, envia-me a mim."

Pollock (2004, p. 50) afirma que este "'chamado' deve ser de Deus, não da propaganda. A decisão de ir deve ser em resposta à questão de cada indivíduo: 'Senhor, o que queres que eu faça?’". Considera-se este um assunto muito delicado para ser tratado, pois missionários, em sua grande maioria, são vistos como sendo "super-heróis". Muitas vezes, são vistos pela comunidade como pessoas que deixam seus lares aconchegantes, a vida financeiramente estabilizada, a sua cultura, a língua nativa, e trocam por uma vida de aventura. Nesta "aventura", possuem um acesso mais restrito à saúde, como o saneamento. E seus recursos financeiros, muitas vezes, são limitados. Imergem em uma cultura com costumes totalmente diferente dos seus. Muitas vezes, aprendem um idioma novo e vivem no meio de um povo esquecido pela sociedade. São considerados heróis pelo fato de fazerem algo que a maioria não tem coragem de fazer.

No entanto, os missionários são seres humanos com necessidades físicas, psíquicas e emocionais. Olhando para este lado humano e frágil dos missionários, é possível que existam preconceitos que precisam ser quebrados, tanto do lado da igreja, como por parte do próprio missionário. O trabalho, muitas vezes é solitário, e o simples falar e ouvir das frustrações, medos e inseguranças do missionário podem ser considerados um sinal de fracasso ministerial.

${ }^{3}$ Todas as passagens bíblicas deste trabalho, quando não especificadas, foram extraídas da Bíblia de Estudo Almeida, Revista e Atualizada, SBB, 1999. 
O missionário também possui necessidades de relacionamento. Não existe nada de "super" no homem, na tentativa de viver sua vida na individualidade. O homem, em geral, precisa reaprender a viver em sociedade, pois, com o avanço da tecnologia ele tem se tornado cada vez mais autossuficiente, e deixou de pensar no coletivo, compartilhar seus problemas, ouvir e valorizar conselhos. As igrejas, ou agências missionárias precisam, neste sentido, estar mais bem preparadas e capacitadas para orientar, direcionar e enviar pessoas para o campo missionário.

O objetivo geral deste trabalho é compreender melhor os fatores que podem levar missionários ao desgaste emocional no campo missionário, e identificar como a igreja pode atuar para que este desgaste seja minimizado. E, pretende-se identificar, também, qual deve ser a postura do missionário para se manter emocionalmente saudável. Pretende-se compreender se a ideia de missionário mártir é a única que as pessoas, nas igrejas, têm. É necessário saber se esta ideia deve ser reavaliada, tendo em vista o problema principal deste trabalho que é a saúde emocional do missionário. Desta forma, se responderia por que os missionários sofrem e o que a propagação do evangelho perde ou ganha com isso.

No entanto, torna-se necessário encontrar sugestões que as igrejas poderiam adotar para uma melhor retenção de seus missionários no campo com base no amor, proclamado pelo próprio Cristo, aos irmãos missionários enviados. Quais ações poderiam ser tomadas pelas igrejas e agências missionárias? Um missionário que serve por sete anos em uma organização missionária e adoece emocionalmente, reluta quando surgem muitos questionamentos de como tudo poderia ser diferente. O que esse missionário poderia ter de fazer para evitar isso? O que a organização ou a igreja poderiam ter feito?

Para atingir os objetivos, esse texto está sistematizado nos seguintes tópicos: Os missionários são, de fato, super-heróis? De onde vem essa ideia?; O que a Bíblia fala sobre o sofrimento do missionário; Missionário Mártir - o significado do sofrimento; A realidade do missionário quanto ao cuidado; $\mathrm{O}$ papel da igreja no cuidado do missionário; Ações de ajuda para os missionários.

\section{OS MISSIONÁRIOS SÃO, DE FATO, SUPER-HERÓIS? DE ONDE VEM ESTA IDEIA?}

Quando igrejas ou pessoas enviam missionários ou missionárias para o campo, a impressão que se tem, de um modo geral, é de que esses enviados são espiritualmente superiores e plenamente capazes de darem conta sozinhos de todos os percalços a que estão sujeitos num campo missionário. Oliveira (2012a, p. 19), falando sobre a percepção que a comunidade cristã 
tem dos seus líderes, afirma que ela possui visões distorcidas quanto à figura dos mesmos. E afirma ainda que estes "por vezes não são percebidos como pessoas, mas como semideuses, não sujeitos ao cansaço, enfermidades e irritações, entre outras mazelas". Talvez seja por causa desta visão, que muitas vezes, as pessoas não sabem lidar com situações onde o missionário não deu conta de algum trabalho ou quando passa por dificuldade.

Buscando melhor entender de onde pode vir esta ideia do trabalho solitário do missionário, uma das razões, talvez questionável, pode estar nos modelos de trabalho adotados por agências missionárias tradicionais, que, conforme dizem Donovan e Myors (1998, p. 61), foi herdada pela geração dos boosters. Os autores consideram como boosters a geração dos que nasceram entre 1927 e 1945, que "cresceram em um mundo que passara pela Grande Depressão e a Segunda Guerra Mundial." Os autores afirmam, também, que eles "eram muito trabalhadores, objetivos, perseverantes, comprometidos, estáveis, frugais e dispostos a arregaçar a manga [...] para alcançar o alvo." Os autores continuam dizendo que "individualistas, independentes e austeros, os boosters conquistaram avanços espantosos do evangelho em áreas antes não alcançadas." Olhando para este modelo de trabalho missionário, implantado pela geração dos boosters, pode ser que se tenha hoje a ideia de que o missionário seja um herói e, portanto, deveria conseguir lutar sozinho.

Prefaciando o livro de Van der Meer (2009, p.8), Osmar Ludovico da Silva afirma que, "nem sempre se considerou que o mais importante em missões é a pessoa do missionário. Não se trata de um herói, mas de um ser humano com suas carências, dores e dificuldades." Para Stott (2007, p. 174), até mesmo "Jesus não era um super-homem imune às fragilidades dos mortais comuns. Ele era um ser humano autêntico". O fato de alguém decidir pela carreira de missionário, não torna esta pessoa mais importante ou mais valiosa do que as pessoas em geral. Ela continua sendo um ser, criado a imagem e semelhança de Deus, conforme o livro bíblico de Gênesis 1.26, com todas as limitações, as quais, as pessoas, por serem humanas, estão sujeitas.

Neste sentido, Van der Meer, afirma:

\footnotetext{
VIVER PERIGOSAMENTE É ALGO QUE MISSIONÁRIOS E HERÓIS TÊM EM COMUM. No entanto, nunca vimos um membro da Liga da Justiça falando de frustrações ou sofrimento. Em geral os super-heróis, casados ou solteiros, se adaptam a qualquer contexto, fazem tudo sozinhos e riem por último. Com os missionários não é assim.

Missionários voltam para casa, para suas igrejas, às vezes, antes de terminarem a missão. Eles precisam de ânimo, de convicção do chamado, de apoio familiar, de cuidado pastoral e, ao contrário dos heróis, de descanso (VAN DER MEER, 2009, contracapa).
}

Da mesma forma, como os super-heróis, em sua maioria, os missionários também acabam 
fazendo tudo sozinhos. Talvez não estejam física ou financeiramente sozinhos, porém se encontram emocional e espiritualmente abalados, como se estivessem abandonados. "As pessoas não esperam ouvir que os missionários estão sofrendo" afirma Van der Meer (2009, p. 130). Exatamente pelo contrário, "as igrejas esperam que seus missionários sejam pessoas especialmente capacitadas por Deus, que apresentem grandes histórias de sucesso" (ibid, p. 111). Oliveira (2012a, p. 87) acrescenta, ainda, que pastores hoje são vistos como "alguém abnegado e disponível todo o tempo". Talvez seja por causa desses pensamentos, muitas vezes enraizados nas igrejas, que os missionários acabam trabalhando e sofrendo sozinhos, buscando "rirem por último", para, quem sabe, se sentirem aptos e aceitos pelas suas comunidades e seus enviadores.

O que acontece, na prática, como afirmou Van der Meer (2009, p. 114), é que, muitas vezes, eles voltam antes do tempo que eles mesmos, a igreja ou a agência missionária haviam estipulado. A autora também afirma que, em geral, os missionários estão dispostos a darem o seu melhor, mas se sentem sem direção e limitados para o serviço. Este retorno prematuro pode estar relacionado ao fato de carregarem as responsabilidades do trabalho de forma solitária e individual. Ainda, com base em uma de suas pesquisas, a autora afirma que uma das principais razões para a volta prematura de missionários brasileiros do seu campo de atuação está relacionada ao escasso cuidado pastoral oferecido a eles (VAN DER MEER, 2009, p. 131). Isso reflete diretamente na questão de carregar, sozinho, os problemas e desafios do trabalho missionário.

Os missionários são, de fato, considerados pessoas especiais pela igreja e pelo corpo de crentes e, até mesmo alguns se autoconsideram especiais. Eles carregam, muitas vezes, de forma solitária a tarefa de todos os convertidos a Cristo, que é a de falar das obras de Cristo e da vida eterna que Ele oferece. É necessário, no entanto, entender que não se deve olhar para o indivíduo como sendo um super-herói ou não, mas sim, ver o que Cristo está fazendo naquela pessoa e através dela. Uma vez, entendendo-se que, segundo a Bíblia, a obra de Cristo é que deve ser enfatizada, e não a obra do missionário como indivíduo, fica mais fácil juntar forças para o trabalho de evangelização e serviço em nome de Cristo.

\section{O QUE A BÍBLIA FALA SOBRE O SOFRIMENTO DO MISSIONÁRIO}

Quando o assunto é vida missionária, as pessoas logo entendem que é uma vida cheia de aventuras e emoções. O trabalho missionário, para algumas pessoas, acontece como um "romance" ou "conto de fadas", pois, o que normalmente ouvem dos próprios missionários são somente as histórias de sucesso, que, de alguma forma, representam um “final feliz". Por outro lado, estas pessoas estão conscientes que o trabalho não é fácil, pois, se este fosse o caso, 
existiriam muito mais pessoas optando por seguir uma vocação missionária.

Em momento algum, na Bíblia, existe o relato de que o trabalho missionário, de propagação do Evangelho de Cristo, seria um trabalho cheio de glórias e honras para a pessoa do missionário ou do cristão. Pelo contrário, no evangelho de João 15.19, Jesus diz: "se vós fosseis do mundo, o mundo amaria o que era seu; como, todavia, não sois do mundo, pelo contrário, dele vos escolhi, por isso, o mundo vos odeia." Jesus quando falava com seus discípulos alertava para dificuldades, como diz no evangelho de João 16.33: "No mundo, passais por aflições; mas tende bom ânimo; eu venci o mundo". Neste sentido, Van der Meer (2009, p. 15) afirma que os missionários são chamados a deixarem suas vontades, e seguirem o caminho de Jesus para a cruz, onde iriam sofrer e serem odiados pelo mundo, com o propósito de testemunhar sobre a nova realidade do reino de Cristo. Pois, "o próprio Jesus sofreu quando aceitou nossa natureza, enfrentou nossas tentações, viveu nossa tristeza e dor, levou sobre si nossos pecados e morreu a nossa morte."

Conforme Van der Meer (2009, p. 21), Jesus passou por sofrimentos físicos, emocionais e relacionais. A autora afirma, ainda, que a vida de Jesus com os seus discípulos foi de transparência, e, no seu relacionamento com eles, Jesus ensinou e preparou os discípulos através de suas experiências próprias (ibid., p. 25). Ao mesmo tempo em que Jesus ensina através do seu sofrimento, ele traz esperança e conforto quando afirma, no evangelho de Matheus 11.28-30, que os cansados e sobrecarregados podem ir ao seu encontro, e acharão descanso para as suas almas, pois o seu jugo e seu fardo são leves.

O profeta Elias, como relatado no livro de 1Reis 19.1-18, é um exemplo da fragilidade de um homem de Deus, como afirma Wieseman (2006, p. 151): "Elias apresentou sintomas de maníaca-depressão, desejo de morte, associadas à perda de apetite, falta de controle, e excessiva autopiedade". Champlin (2000, p. 1443) fala, ainda, de uma atitude "de caverna" onde "tanto o seu coração e sua mente se tinham escondido, e não somente o seu corpo. Ele era prisioneiro de suas emoções negativas, e seu desespero o amarrava como se [fosse] uma corrente de ferro". O que acaba sendo reconfortante, neste episódio da vida de Elias, é que Deus não o abandonou, mas restaurou as suas forças. Elias queria se esconder nas "cavernas", mas Deus, de forma graciosa e amorosa, o alimenta, dá descanso e o chama para fora da caverna e lhe comissiona uma nova tarefa. Com isso, Elias é restaurado por completo.

O apóstolo Paulo, com certeza, é um dos grandes exemplos do que é ser um missionário. A sua dedicação ao trabalho missionário contribuiu de forma exemplar, para que o evangelho de Cristo fosse pregado e ensinado no seu tempo, e que até os dias de hoje orientam no ensino da igreja. Apesar de todo o seu status perante o trabalho missionário e perante as igrejas, "Paulo nã 
o omitiu sua fraqueza ou sofrimento, porque sabia que Deus transforma seres humanos fracos em instrumentos de sua graça" (VAN DER MEER, 2009, p. 34).

Da mesma forma, a Bíblia, em 2Coríntios 12.9-10, deixa claro que o apóstolo Paulo, através do seu exemplo, demonstra que o fato de falar de suas fraquezas e sofrimentos não torna ele mais fraco ou menos importante para o trabalho de propagação da mensagem redentora de Cristo. Ele afirma que, nestes momentos de fraqueza humana, Deus mostra a sua força.

"Sofrimento e morte não são meritórios em si mesmos," afirma Van der Meer (2009, p. 35). "O único motivo válido é 'pelo nome de Jesus'." A autora afirma, ainda, que o verdadeiro sofrimento é aquele que acontece de acordo com a vontade de Deus, segundo 1Pedro 4.19. Este texto diz: "Por isso, também os que sofrem segundo a vontade de Deus, encomendem a sua alma ao fiel Criador, na prática do bem." Assim, segundo a Bíblia, há mérito em alguns tipos de sofrimentos, se forem segundo a vontade de Deus, e não por si mesmos. A autora argumenta que o verdadeiro sofrimento é também em nome de Jesus Cristo conforme Filipenses 1.29: "Porque vos foi concedida a graça de padecerdes por Cristo e não somente de crerdes nele," e, ela acrescenta que é também por causa do evangelho, citando o texto de 2Timóteo 1.8 que diz: "[...] participa comigo dos sofrimentos, a favor do evangelho, segundo o poder de Deus [...]."

Assim, quando o missionário busca viver e agir de acordo com a vontade de Deus, os sofrimentos se tornam suportáveis e, muitas vezes, superáveis, pois ele entende que a obra não é humana, mas sim divina. Isso implica em reconhecer a soberania de Deus, independente de sofrimento ou glória pessoal. Jesus afirma que os homens devem se amar mutuamente, assim como ele os amou. Ele demonstrou o seu amor por meio do sofrimento, quando entregou a sua vida para morrer pelos seres humanos (Jo 15.12-13). Van der Meer (2009, p. 58) afirma que, amar uns aos outros, "como Cristo nos amou, geralmente não leva a ações espetaculares, mas ao ministério prático de carregar as cargas uns dos outros."

No entanto, a autora lembra sobre a tentação como parte do sofrimento humano.

Temos um inimigo que está presente quando nos sentimos fracos e desanimados, e que
nos oferece uma saída fácil; ou quando recebemos elogios e reconhecimento, ele nos
estimula a nos sentirmos autossuficientes. Isto leva os cristãos em missão a erros sérios
ou ao pecado, luta, pressão e sofrimento (VAN DER MEER, 2009, p. 17).

Portanto, diante das inúmeras possibilidades de sofrimento, quando está em missões, o missionário, como indivíduo, precisa estar sempre atento, e vigiando para que ele não passe por "falsos sofrimentos", em oposição aos verdadeiros sofrimentos pelo evangelho, mas para que ele possa permanecer sempre firme em Cristo, conforme testifica o evangelho de Lucas 21.36. 


\section{MISSIONÁRIO MÁRTIR - O SIGNIFICADO DO SOFRIMENTO}

O The Center for the Study of Global Christianity (CSGC - Centro de Estudos do Cristianismo Global), respondendo à pergunta "Why do you report such high figures for Christian martyrs?" (2015) $)^{4}$ (Por que reportar números tão altos para mártires cristãos?) estima que mais de 70 milhões de cristãos foram martirizados na história, e mais da metade destes aconteceram no século 20 debaixo dos regimes fascistas e comunistas.

Segundo um resumo do artigo de Johnson e Zurlo (2014), intitulado de "Christian Martyrdom as a Pervasive Phenomenon" (O martírio cristão como fenômeno penetrante), estimase que, no início do século 21, entre os anos de 2000 e 2010, houve uma média de 100 mil mártires por ano, totalizando o número de 1 milhão em dez anos. Estes dados estão baseados em critérios específicos que englobam os crentes em Cristo que perderam suas vidas prematuramente em situações de testemunho, como resultado da hostilidade humana, segundo os autores.

Na história, por causa dos mártires, e até mesmo nos dias de hoje, quando se ouve falar de alguém que morreu pela fé cristã, esta pessoa passa a ser tida como um exemplo a ser seguido por outros missionários. Conforme Van der Meer (2009, p. 108), "a igreja primitiva considerava o martírio um chamado especial em momentos de perseguição e expansão." A autora afirma que, "a alegria do martírio veio da percepção de que teriam a honra de sofrer pelo Senhor. Havia uma intimidade extraordinária entre Deus e o sofredor, fato que deu novas forças aos mártires" (ibid., p. 109).

Van der Meer (2009, p. 110) lembra que Lutero considerava que a igreja verdadeira era a igreja dos mártires. Ela também lembra que, os anabatistas diziam que "o sofrimento era considerado uma prova de veracidade e o martírio um sermão que tocava os corações". Como se pode observar, a valorização do martírio não é algo recente, mas é passado de geração em geração.

Cada cristão deve tomar a sua cruz e seguir a Jesus. Neste sentido, Fernando (2004, p. 181) fala do desejo de Jesus, que os seus seguidores tenham a mesma alegria dele. Alegria esta, que inclui um estilo de vida, no qual o tomar a cruz está implícito. Baseado no texto de João 15.1113, o autor afirma que Cristo fala do amor em sua forma suprema onde uns morrem pelos outros. No entanto, em primeiro lugar, deve haver alegria. Além disso, a alegria tem a ver com serviço sacrificial. Ele complementa que, "se fomos enviados ao mundo como o Pai enviou Jesus (Jo 20.21), então, nós também devemos morrer pelas ovelhas que Deus nos confiou."

Quando se fala de sofrimento na vida do missionário, logo se pensa em perseguição. Segundo Van der Meer (2009, p. 110), o tema da perseguição é complexo. Ele "pode produzir

\footnotetext{
${ }^{4}$ GORDON-CONWELL RESOURCES. Why do you report such high figures for Christian martyrs? 2015. Disponível em: <http://www.gordonconwell.edu/ockenga/research/Quick-Facts-about-Global-Christianity.cfm\#7>. Acesso em: 19/10/2017.
} 
uma nova unidade e solidariedade e ajudar pessoas a amadurecerem na fé." Por outro lado, "alguns líderes que foram corajosos ao enfrentar perseguições podem ser tentados a pensar que fazem parte de uma elite espiritual e achar que têm uma autoridade especial." Portanto, a veneração daqueles que sofrem por causa do testemunho deve ser evitada.

Em algumas passagens bíblicas, "quando Jesus é apresentado como modelo para os cristãos, muito frequentemente, esse é um modelo de sofrimento (Jo 15.12-13; Hb 12.2; 13.12-13; 1 Pe 2.1924; 4.1-2)" (FERNANDO, 2004, p. 181). Ao mesmo tempo, tendo Jesus como modelo, Van der Meer (2009, p. 111) afirma que a vida missionária é um privilégio. Porém, "é uma carreira que tem um alto custo. Há muitos desafios, o estresse está sempre presente e com frequência envolve sofrimento. Por isso, os missionários precisam de compreensão e apoio amoroso".

Nos dias atuais, com o impacto da teologia da prosperidade na sociedade, conforme Van der Meer (2009, p. 153), as pessoas se acostumaram a esperar bênçãos imediatas, “e não aprenderam sobre a sua responsabilidade de serem testemunhas na sociedade. [...] O sofrimento é visto como resultado de falta de fé ou como consequência de pecado." A autora complementa que devido à influência desta teologia, "tornou-se difícil para os missionários que passam por dificuldades e lutas receberem apoio e compreensão".

O sofrimento e o martírio nunca deixaram de fazer parte da vida do cristão, como mostram os dados do Centro de Estudos do Cristianismo Global, e também não são exclusivos da vida do missionário. Eles devem acontecer pelos motivos corretos, que envolvem os dois grandes mandamentos, primeiro amar a Deus e em segundo lugar amar ao próximo (Mt 22.37-40), e não pelo reconhecimento social e amor próprio.

O sofrimento por Cristo é visto como algo positivo na vida do missionário. Porém, para que possa haver crescimento pessoal e da igreja, ele deve ser compartilhado. Taylor (1998, p. 349) afirma que as emoções e experiências dolorosas do campo não devem ser escondidas e sim, enfrentadas. Pois, agindo assim, pode ser encontrada a valiosa ajuda por meio de um orientador espiritual ou conselheiro. Quando o peso de uma carga é dividido, a caminhada se torna mais agradável e é possível ir mais longe.

O martírio, por si só, nunca vai deixar de gerar impacto sobre a vida das pessoas e da comunidade. Mortes pela causa de Cristo sempre terão um impacto forte e positivo na comunidade evangélica. É como se essas experiências enfatizassem que vale a pena seguir Jesus. No entanto, devido às influências de teologias ensinadas na atualidade, o sofrimento tem adquirido uma conotação diferente na vida dos cristãos. Em algumas teologias, o sofrimento significa que a pessoa está afastada de Deus, está em pecado e tem pouca fé. 
Por estes motivos, os cristãos, incluindo os missionários, muitas vezes sofrem calados e de forma solitária. No entanto, o conceito de sofrimento precisa ser reavaliado pelas igrejas e líderes eclesiásticos. O sofrimento em suas diversas formas vai sempre fazer parte da vida dos missionários, como de qualquer cristão. $\mathrm{O}$ apóstolo Paulo já falava que o sofrimento presente não pode ser comparado com a glória a ser revelada ( $\mathrm{Rm} 8.18)$. Na carta de Tiago, ele afirma que as provações devem ser motivos de alegria, pois produzem a perseverança (Tg 1.2-3). O sofrimento não é solitário e individual como diz na primeira epístola de Pedro 5.9: "resisti-lhe [ao diabo] firmes na fé, certos de que sofrimentos iguais aos vossos estão se cumprindo na vossa irmandade espalhada pelo mundo". Por este motivo, os missionários, não precisam e nem devem sofrer sozinhos. Eles precisam encontrar pessoas com as quais possam dividir as suas cargas, para que a caminhada não seja tão exaustiva e venham a sucumbir antes de alcançar o alvo.

\section{A REALIDADE DO MISSIONÁRIO QUANTO À NECESSIDADE DE CUIDADO}

A Bíblia, no texto de Gálatas 6.2 diz: "levai as cargas uns dos outros e, assim, cumprireis a lei de Cristo". A necessidade de compartilhar as cargas uns dos outros, deve ser considerada, tanto pelo missionário, como pela agência e igreja enviadora do mesmo. Collins (2004, p. 16), levando em consideração as expressões "uns aos outros", apresentadas na Bíblia, afirma que, "a assistência ao próximo não era [para os escritores da Bíblia] uma questão de opção, mas uma responsabilidade de cada crente, inclusive do líder da igreja."

Oliveira (2012b, p. 94) afirma que "nascemos em comunidades, vivemos em comunidades, morremos em comunidades. Nós seres humanos não somos criaturas solitárias e autossuficientes". Porém, o que se percebe sobre esse cuidar e se preocupar com as necessidades do próximo, no geral, é que a comunidade evangélica tende a lançar todas as suas expectativas na pessoa do pastor ou nos missionários. Se fosse para ser assim, quem cuidaria das necessidades físicas, psíquicas e emocionais desses?

A falta de um cuidado pastoral e/ou a falta de uma supervisão adequada para com os missionários e suas famílias, muitas vezes, pode causar o seu retorno prematuro do campo. Kang (1998, p. 227) afirma, de acordo com o relatório da pesquisa feita pela Comissão de Missões da Aliança Evangélica Mundial (AEM) como parte do seu Projeto de Redução da Perda de Missionários (ReMAP), apresentado no quadro da figura 1 , que a inadequada supervisão e cuidado pastoral são responsáveis por grande parte das causas de retorno prematuro nos NPE [Novos Países Enviadores, do qual o Brasil faz parte].

\footnotetext{
${ }^{5}$ NPE são considerados os "novos países enviadores", que tem uma história mais jovem em missões modernas. Entre eles estão Gana, Nigéria, Costa Rica, Brasil, Índia, Coréia do Sul, Filipinas e Singapura.
} 
Olhando para esse quadro, que aponta para prováveis problemas que afetam a perda de missionários no campo, relacionado com o cuidado pastoral e supervisão, deve-se questionar se o que motiva este abandono prematuro do campo tem a ver somente com falta de cuidado pastoral, ou se existem outros fatores envolvidos. Pensando nos problemas familiares, quando o missionário ou família tem problemas de saúde, dificuldades com os filhos, com os pais idosos, e com questões pessoais, ou até mesmo com o casamento fora da missão, com alguém sem as mesmas convicções de ministério, uma atenção especial de suporte da igreja pode ser importante para encontrar soluções para superar estas dificuldades. Na questão de problemas espirituais, um acompanhamento mais próximo de amizade e não julgamento pode trazer força, revigoramento e amadurecimento para o missionário.

No quesito ministério, um acompanhamento mais próximo das atividades, uma compreensão das dificuldades e barreiras encontradas podem trazer soluções e consequentemente um trabalho mais eficiente o campo missionário.

QUADRO 01: Perda de missionários.

\begin{tabular}{|c|c|c|c|c|}
\hline \multicolumn{5}{|c|}{$\begin{array}{c}\text { PERDA DE MISSIONÁRIOS NOS NPE EM RELAÇĀO } \\
\text { COM CUIDADO PASTORAL E SUPERVISĀO }\end{array}$} \\
\hline \multicolumn{2}{|c|}{ Categoria } & Fator de retorno & $\%$ & Total \\
\hline \multirow{6}{*}{$\begin{array}{c}\mathrm{F} \\
\mathrm{A} \\
\mathrm{M} \\
\mathrm{i} \\
\mathrm{L} \\
\mathrm{i} \\
\mathrm{A}\end{array}$} & \multirow{20}{*}{$\begin{array}{c}M \\
1 \\
N \\
1 \\
S \\
T \\
\hat{E} \\
R \\
1 \\
O\end{array}$} & Problemas de saúde & 5,1 & \\
\hline & & Filhos & 4,8 & \\
\hline & & Questões pessoais & 4,5 & \\
\hline & & Casamento fora & 4,0 & \\
\hline & & Pais idosos & 1,3 & \\
\hline & & Conflitos conjugais/familiares & 2,8 & \\
\hline & & Falta de chamado & 8,0 & \\
\hline & & Compromisso inadequado & 7,3 & \\
\hline & & Imaturidade espiritual & 4,5 & \\
\hline & & Vida imoral & 2,2 & \\
\hline & & Problemas com colegas & 5,7 & \\
\hline & & Problemas com líderes locais & 4,0 & \\
\hline & & Insatisfação com o trabalho & 2,2 & \\
\hline & & Demissão pela agência & 2,5 & \\
\hline & & Supervisão inadequada & 2,3 & 5,4 \\
\hline & & Dific. de adaptação cultural & 3,0 & \\
\hline & & Dific. em aprender a língua & 1,5 & \\
\hline & & Falta de sustento & 8,1 & \\
\hline & & Desacordo com a agência & 6,1 & \\
\hline & & Total & 79,9 & \\
\hline
\end{tabular}

Fonte: Kang (1998, p. 228).

Oliveira, falando dos benefícios de um acompanhamento mais próximo, afirma:

Dentro do limite da história pessoal, o olhar do outro ou dos outros irá traduzir para o Eu novas possibilidades e remanejos de pensamentos e atitudes. Neste sentido, a supervisão, o mentoreamento, o coaching são da maior importância, embora ainda não praticados pela maioria dos cuidadores (OLIVEIRA, 2012b, p. 103). 
Tostes (2004, p. 91), citando a pesquisa que foi discutida no livro "Valioso demais para que se perca", aponta que "dentre as principais razões para o retorno prematuro de missionários enviados pelo Brasil estão os problemas pessoais relacionados ao caráter do missionário." Lewis (1998, p. 112), com base no relatório da pesquisa da Aliança Evangélica Mundial (AEM) na consulta sobre a ReMAP, afirma que, no Brasil, o treinamento inadequado é apontado como a principal razão deste retorno.

Em se tratando do retorno prematuro do missionário, "a igreja, a agência e o centro de treinamento precisam começar a dialogar para ver como podem integrar melhor seus recursos" (GIRÓN, 1998, p. 56). Considerando que mais da metade dos fatores de retorno prematuro são espirituais e de caráter, Adiwardana (1998. p. 185) alerta que, o "treinamento formal e não formal anterior ao campo precisa dar ênfase na formação do ser". Nesse sentido, Tostes (2004, p. 91) afirma que existem missionários sendo enviados sem um preparo adequado, e tanto eles, quanto os envolvidos acabam pagando um alto preço por isso. A autora (2004, p. 92) afirma, ainda, que "igrejas enviadoras e agências missionárias estão ficando mais conscientes de que o cuidado é necessário desde o recrutamento até a aposentadoria."

Pollock (2004, p. 50) complementa que "o fluxo do cuidado começa com o relacionamento dos missionários em potencial com o corpo local de crentes e se move para o relacionamento com a agência enviadora." Para Tostes (2004, p. 92) é preferível que o missionário cresça em casa, do que mais tarde caia no campo. Luna $(2004$, p. 81) considera que existem duas áreas preocupantes no recrutamento de novos missionários Latino-Americanos: "A primeira é a maneira errada de recrutar pessoas para as missões; a segunda envolve as motivações erradas em alguns desses jovens." Por estas razões, se faz importante que o início da vida do missionário aconteça em casa, com a sua igreja local.

Considerando a motivação da pessoa para seguir o chamado missionário, Pollock (2004, p. 50), com base no texto bíblico de 1Coríntios 1.9, que diz: "Fiel é Deus, pelo qual fostes chamados à comunhão de seu Filho Jesus Cristo, nosso Senhor", ressalta que, primeiro o candidato deve ter comunhão adequada com o Senhor Jesus, para depois sair para o campo missionário. O autor (2004, p. 53) afirma, ainda, que boas decisões são baseadas em uma boa preparação.

Olhando para o relacionamento de Jesus com os seus discípulos, Adiwardana (1998, p. 185) aponta para a estratégia de ensino de Jesus, que envolvia a seguinte ordem: ensinar, pregar, explicar, corrigir, fazer e enviar. E ressalta que, o "conhecer leva a ser, e resulta em fazer. Fazer traz subsídios para corrigir." E esse processo só pode funcionar adequadamente com o trabalho conjunto entre igreja, escola e agência missionária. 
Em todo esse processo de preparo e envio, o missionário precisa de apoio e orientação de conselheiros capacitados e, segundo Pollock (2004, p. 53), "conselheiros-chaves, neste estágio, são pessoas como os treinadores transculturais, missionários experientes e outros que podem melhor preparar os novos missionários." Uma vez enviados ao campo, Tostes (2004, p. 93) fala da importância de os missionários saberem que não foram esquecidos e que as pessoas de seu país e no campo se importam com eles. A autora (2004, p. 94) alerta, ainda, sobre o perfil de candidatos mais propensos aos conflitos e fracassos, que são aqueles "acostumados com os confortos da vida, pouco sofrimento e uma mentalidade e estilo de vida que valorizam o sucesso, riqueza e respostas rápidas". Isso reforça a importância de todo o processo que envolve o envio do missionário ao campo. É necessário conhecer o missionário em sua integridade para, dessa maneira, poder oferecer o cuidado necessário quando estiver no campo.

Com a sua chegada ao campo, o missionário se depara com as dificuldades reais do lugar, e que, muitas vezes, fogem daquilo que foi previsto no seu preparo. Agora começam os verdadeiros desafios da vida missionária e, por isso, a grande importância da continuidade no cuidado deste missionário. Van der Meer (2009, p. 156), analisando a sua pesquisa e influenciada por sua experiência de dez anos em Angola (1985 a 1995), fala dos missionários naquela região afirmando que, a maioria "recebeu pouco cuidado pastoral, e alguns retornaram para seus países de origem desgastados, enquanto outros permaneceram fiéis, mas, muitas vezes, a ponto de terem um colapso emocional." Donovan e Myors (1998, p. 59) afirmam que, "muitos missionários retornam com o coração partido e o espírito arrasado. Isto não é apenas uma perda importante para missões, mas uma tragédia pessoal para os envolvidos." Essa afirmação ressalta a importância do cuidado para com a pessoa do missionário.

Van der Meer (2009, p. 11) afirma que vários missionários que enfrentam dificuldades e sofrimento no campo, recebem pouco apoio prático e pouco cuidado pastoral. Falando de missionários que lutam com a depressão, a autora $(2009$, p. 12) afirma que "a maioria [...] enfrenta incompreensão e trava uma batalha árdua e solitária para superar a dor." O’Donnell (2004, p. 25) concorda que os missionários precisam ser cuidados, para que eles "possam efetivamente amar, evangelizar e discipular os grupos, aguentar as dificuldades e crescer com o povo".

Para a pergunta de quem irá fazer todo este cuidado, que vai desde o preparo, envio, retorno e aposentadoria, O'Donnell responde:

\footnotetext{
Líderes (igreja e agências) que dedicam o tempo para seu próprio pessoal. Pessoas como especialistas do desenvolvimento pessoal, diretores de campo, pastores, estrategistas e treinadores transculturais, que estão disponíveis a sustentar e melhor equipar nosso pessoal. E, finalmente, colegas e amigos - você e eu - cujo encorajamento mútuo se torna a espinha dorsal para os efetivos programas de cuidado missionário (O'DONNELL, 2004, p. 22).
} 
Considerando esse cuidado integral do missionário, percebe-se que ele não se limita aos líderes de igrejas e agências missionárias. O cuidado envolve toda a comunidade de cristãos, desde a família, amigos e profissionais. Existe também a necessidade de que os próprios missionários ou pastores, como afirma Oliveira (2012a, p. 90), sejam "humildes e reconheçam as suas limitações e, quando necessário, busquem ajuda". A igreja como um todo deve estar e ser envolvida no cuidado integral dos missionários.

\title{
5 O PAPEL DA IGREJA NO CUIDADO DO MISSIONÁRIO
}

Em uma sociedade egocêntrica como a atual, quase tudo gira em torno das vontades e desejos pessoais. As pessoas se tornaram individualistas. Cada uma é dona de sua própria verdade. O que realmente importa para a pessoa é satisfazer os seus desejos pessoais, independentemente do impacto que isso tenha na vida de outra pessoa, tornando-a esquecida, denegrida ou humilhada. Neste sentido, Oliveira afirma que:

\begin{abstract}
Vivemos hoje a religião do $\mathrm{Eu}$, do individualismo. O universo é um grande supermercado; somos um cosmo que consome. Vive-se como se a eternidade fosse agora; parece que perdemos a noção da transitoriedade. No culto do Eu, ensina-se o "seja feliz" de forma egoísta e não integral. Pessoas e funções são usadas em relações utilitárias, nas quais, se um ganha mais, outros perdem. E uma devoção, pois cria a ilusão do poder pessoal, de que podemos determinar o que podemos ter: [...] Nesse narcisismo extrapolado, no qual as relações giram em torno do Eu, o próprio ser é visto e sentido como sendo coisa, e não pessoa (OLIVEIRA, 2012b, p. 19,20)
\end{abstract}

Considerando os ensinamentos bíblicos, o individualismo e egocentrismo não são encontrados como exemplos a serem seguidos. O texto bíblico de Colossenses 1.8 diz que Cristo é a cabeça do corpo, e o corpo é a igreja. Utiliza-se a figura de um corpo para descrever a igreja, o qual é composto por muitos membros. A Bíblia diz em 1Coríntios 12.26 que, "[...], se um membro sofre, todos sofrem com ele; e, se um deles é honrado, com ele todos se regozijam." Lembrando também dos ensinamentos envolvendo a expressão "uns aos outros", a igreja precisa voltar a pensar no coletivo, e não se deixar influenciar pela sociedade individualista.

A relação que muitas igrejas têm com o cuidado missionário reflete diretamente a maneira de pensar e agir do líder local. Van der Meer (2009, p. 130), mencionando um pastor que trabalha oferecendo cuidado pastoral a missionários latino-americanos em vários campos, diz que, "os pastores latino-americanos consideram que os missionários são maduros e não precisam de cuidado pastoral." Contradizendo esse pensamento de muitos pastores latino-americanos, Girón (1998, p. 54) afirma que, "o trabalho pastoral requer líderes de campo voltados para pessoas e não só para alvos." O autor (1998, p. 55) afirma ainda, que, "incentivando os membros da igreja a 
manter contato com seus missionários, o pastor está contribuindo para o sustento moral do missionário." Van der Meer (2009, p. 67) incentiva a igreja a "aceitar esse desafio missionário e aprender a apoiar e cuidar melhor de seus servos, que ministram o amor de Cristo àqueles que sofrem."

Sendo bem realista quanto à perda de missionários, Lindquist (1998, p. 225) não vê um quadro positivo, pois o fato é que sempre se terá perdas de missionários. Van der Meer (2009, p. 129) diz que "os principais fatores na prevenção do retorno precoce do missionário do campo são: convicção de chamado, apoio familiar, relacionamentos saudáveis e cuidado pastoral." A autora (2009, p. 130) afirma, ainda, que, "se receberem apoio e cuidado pastoral adequado, os missionários podem aprender a lidar com seus problemas e dores". Girón (1998, p.54) afirma que "cuidado pastoral e supervisão são essenciais para um trabalho missionário bem-sucedido." Para o autor, as necessidades pastorais envolvem as necessidades pessoais dos missionários, preocupações em relação a filhos, pais ou vida familiar, doenças ou morte do cônjuge.

Para poder servir de forma mais eficiente como apoio para os missionários, a igreja e as agências precisam entender e saber quem são estes missionários. A qual geração eles pertencem, de que contextos sociais e econômicos vieram. Donovan e Myors (1998, p. 60) afirmam que "os missionários de hoje são tão diferentes dos de 30 anos atrás que não se encaixam mais em modelos missionários tradicionais." Eles acrescentam: "em outras palavras, estamos colocando vinho novo em odres velhos [...]. Esta situação está tirando a força tanto dos missionários como das agências missionárias."

Donovan e Myors, preocupados em compreender e ajudar o trabalho missionário junto a atual geração de missionários, afirmam:

\begin{abstract}
$\mathrm{Na}$ atual geração de missionários temos um grupo excelente de jovens muito bem preparados para assumir a tarefa missionária em seu próximo estágio. Todavia, para poderem fazer o trabalho bem feito, como os boosters [geração que proporcionou os moldes de missão adotados até hoje] quando foi a sua vez, eles precisam de muito apoio.

Especificamente, eles precisam de organizações missionárias preparadas para mudar, para recebê-los. Precisam de líderes que lhes confiem o trabalho e funcionem como facilitadores e como inspiração para eles. Precisam do tipo certo de administração e aperfeiçoamento pessoal e profissional para possibilitar o bem-estar pessoal e um ministério de alto padrão. Precisam do tipo certo de apoio para mantê-los no campo quando sua coragem ameaça falhar (DONOVAN; MYORS, 1998, p. 95-96).
\end{abstract}

Existe aqui, a importância da igreja e agências missionárias buscarem entender as novas gerações de missionários, e aprenderem com isso, para que possam oferecer o tipo certo de ajuda. Van de Meer (2009, p. 114) afirma que "os líderes de campo precisam aprender a oferecer aconselhamento e ajudar na solução de problemas." A autora diz que, "quando os líderes 
aprenderem a ouvir seus missionários, compreendendo o contexto onde vivem, e oferecerem cuidado integral, apoio financeiro e orientações práticas, os resultados virão" (ibid., p. 154).

Não basta a igreja enviar missionários ao campo sem se interessar primeiramente pela pessoa no missionário. A igreja é composta por pessoas com características peculiares. Tanto membros como ministros ou missionários têm suas características particulares, e por este motivo é importante entender a ideia de "corpo de Cristo". E cada parte deste corpo tem necessidades diferentes. No entanto é de suma importância, que a igreja entenda que o missionário não é uma "máquina" e sim um membro que tem necessidades específicas e que precisa de cuidados.

\section{AÇÕES DE AJUDA PARA OS MISSIONÁRIOS}

"De ninguém!" Estas foram as palavras de vários missionários à pergunta, "de quem vocês receberam apoio ou cuidado pastoral?", feita em uma pesquisa por Van der Meer (2009, p. 157). Uma vez desmistificada a ideia de que o missionário seja algum tipo de super-herói, ou uma pessoa muito especial, é possível olhar para ele como uma pessoa que foi criada a imagem e semelhança de Deus, como todos os outros seres humanos. E, não são necessários grandes atos para ajuda-los.

O trabalho no campo missionário não deve ser um trabalho solitário de um membro. O trabalho precisa envolver todo o corpo de Cristo, a igreja. Girón (1998, p. 54), afirma que "a supervisão é necessária, para garantir que o trabalho atribuído a cada missionário seja concluído com sucesso, mas, em longo prazo, o trabalho pastoral é ainda mais importante que a supervisão". O missionário precisa, sim, desempenhar bem o trabalho que lhe foi proposto, porém, se ele estiver machucado ou doente o trabalho não será realizado de forma adequada e satisfatória.

Conforme Van der Meer (2009, p. 128), "o cuidado pode se expressar num simples oferecimento para a pessoa tirar alguns dias de férias, numa visita, num telefonema, numa carta de encorajamento, ou num plano de saúde para o missionário." A autora afirma, ainda, que é necessário investir no cuidado do missionário, e "isso significa gastar tempo escrevendo para eles, dando telefonemas, e ajudando-os a encontrar maneiras de solucionar seus problemas" (ibid., p. 132). Oliveira (2012b, p. 53) afirma que "cuidar da alma implica cuidar dos sentimentos, dos sonhos, dos desejos, das paixões contraditórias, do imaginário, das visões e utopias" que estão guardadas nos corações. Oferecendo-se um cuidado contínuo, que acontece por meio de pequenas e simples ações, o missionário se sente encorajado e capacitado para continuar no campo.

A preocupação com o cuidado integral do missionário está se tornando presente em organizações missionárias. Mas, antes que isso aconteça, o missionário, a igreja e a agência 
missionária precisam entender que, "para cuidar de outros, precisamos aprender a cuidar de nós mesmos. Só podemos dar o que temos" (OLIVEIRA, 2012b, p. 28). Existem, no entanto, algumas organizações que já começaram a pensar e agir em relação ao cuidado integral do missionário. Um exemplo disso é a Junta de Missões Nacionais da Convenção Batista Brasileira. Ela tem a sua própria unidade pensando no CIM - Cuidado Integral do Missionário ${ }^{6}$. A Junta de Missões Mundiais (JMM) tem uma Coordenação do Cuidado Integral do Missionário ${ }^{7}$. Existe também o Ministério OASIS ${ }^{8}$, que é um Centro de Aconselhamento Cristão, que tem como principal objetivo o cuidado emocional do missionário e líder cristão. É possível que existam, ainda, outras organizações preocupadas com os seus missionários de forma integral. A grande questão é, se a igreja brasileira tem se ocupado com esta questão. A igreja, quando se preocupa, muitas vezes tem terceirizado este cuidado para com o missionário. Porém, estes ministérios que visam cuidar do missionário, necessitam de recursos para poder oferecer esta ajuda qualificada. Novamente, é possível identificar a necessidade do envolvimento da igreja no cuidado emocional do missionário, também na parte financeira.

Este cuidado para com o missionário e sua família como um todo, é de suma importância para que eles possam se manter saudáveis no campo. Não se considera a ausência de dores, dificuldades e sofrimentos, porém, estes podem ser tratados e enfrentados com uma perspectiva de esperança e não de perda e fracasso. Com a consciência e interesse do missionário em se deixar ser cuidado e da igreja em cuidar, a saúde emocional do missionário pode se manter equilibrada e saudável.

Em momentos e situações onde esta prevenção não foi possível, onde o missionário possa estar no ponto de um colapso emocional, ou mesmo o missionário venha a adoecer emocionalmente, podem se considerar algumas ações de ajuda para o missionário nesta situação. Estas ações podem envolver um tempo de descanso, um período sabático ${ }^{9}$, férias em família em um lugar onde não se espera nada dele. Oferecer um acompanhamento sistemático e regular com um terapeuta neutro ao seu envolvimento missionário. Sugerir leituras direcionadas para o momento que o missionário está passando. Proporcionar uma reciclagem ou atualização dos estudos teológicos ou até mesmo profissionais. Preocupar-se com a sua saúde, um check-up médico, momentos de lazer e atividades físicas. Um convite pode trazer sentimentos positivos de pertencer, ser amado e respeitado como pessoa. O cuidado integral envolve todas as dimensões do ser humano.

Segundo a Organização Mundial da Saúde - $\mathrm{OMS}^{10}$, saúde é um "estado de completo bemestar físico, mental e social e não somente ausência de aflições e enfermidades". Oliveira (2012a,

\footnotetext{
${ }^{6}$ Missões Nacionais - Cuidado integral do missionário: http://www.cuidadomissionariojmn.org.br/quem-somos

${ }^{7} \mathrm{JMM}:$ http://missoesmundiais.com.br/noticias/cuidado-integral-do-missionario/

${ }^{8}$ Ministério Oásis: https://www.ministeriooasis.org.br/

${ }_{9}^{9}$ Período sabático: "O conceito original é você sair do emprego para ter um tempo para se aprofundar em estudos de interesse pessoal: viagens, cursos. É uma iniciativa de autoconhecimento", afirmou o sócio-diretor da LCZ
} 
p. 96) afirma que este conceito começa a sofrer alterações, pois já se começa a falar também na espiritualidade. Assim sendo, qualquer ação que a comunidade cristã tenha em relação à figura do missionário que venha a beneficiar física, mental, social e emocionalmente, estará agindo de forma a recuperar o missionário doente e até mesmo prevenindo que ele venha a adoecer.

É necessário considerar a peculiaridade de cada missionário e família. Cada um demanda um tempo diferente para ser curado. Cada espécie de ferida precisa de um tratamento e tempo específico. Champlin (2000, p. 1443), se referindo ao processo de cura do profeta Elias, diz que ele foi suprido com alimentos de forma miraculosa, porém depois de comer ele tornou a dormir, "pois o seu espírito ainda não estava revivificado". O autor afirma, ainda, que "as curas da alma e da mente também podem levar algum tempo. O anjo [...] tocou em Elias de novo, alimentou-o novamente; e dessa vez, fê-lo levantar-se sobre os próprios pés". Deus tem o poder de curar, alma, espírito e corpo de forma mágica e instantânea, porém Ele convida o ser humano, que foi criado a sua imagem e semelhança, a participar do processo de restauração.

No que diz respeito à saúde emocional do missionário, um dos principais fatores que trazem consolo, conforto e fortalecimento para ele, é poder encontrar um ambiente seguro onde existe a liberdade de falar sobre todas as suas lutas e sentimentos sem ser julgado por suas palavras e pensamentos. Oliveira (2012a, p. 83) afirma que "a dor que não é expressa verbalmente se manifesta de forma psicossomática, ou seja, faz adoecer". O simples fato de ouvir traz muito conforto para o missionário e abre as portas para a cura da alma. Van der Meer (2009, p. 136) ressalta que é necessário "aprender a compreender quando as pessoas já ultrapassaram sua capacidade de suportar a situação e precisam de um tempo de cuidado e descanso."

Zack Eswine (2017), em seu artigo sobre Amizade: remédio de Deus para um ministro esgotado (Parte 1) afirma que "seguir sem amigos no ministério representa um perigo genuíno e nos rouba o fortalecimento interior que Deus intenciona nos dar." Uma das grandes ajudas que o missionário pode ter no trabalho ministerial, é encontrar um amigo que esteja ao seu lado fortalecendo e apoiando em momentos difíceis, e saber que ele não precisa enfrentar as suas lutas na perspectiva de um "super-herói".

\section{CONCLUSÃO}

Os missionários fazem parte do corpo de Cristo, a igreja, e, por isso não devem ser considerados, e muito menos, se autoconsiderarem super-heróis. A consciência de que o maior interessado no trabalho missionário é Cristo, e que é Cristo quem realiza, precisa estar presente,

Desenvolvimento de Pessoas e Organizações e professor da Fundação Vanzolini (USP), Luis Felipe Cortoni. NOTÍCIAS. Você sabe o que é o período sabático? 2008. Disponível em:

$<$ http://www.administradores.com.br/noticias/negocios/voce-sabe-o-que-e-o-periodo-sabatico/16487/>. Acesso em: 26/10/2017.

${ }^{10}$ Conceito de Saúde segundo OMS / WHO. Disponível em: <http://cemi.com.pt/2016/03/04/conceito-de-saudesegundo-oms-who/>. Acesso em 25/10/2017. 
tanto na igreja, como na mente do próprio missionário. O único que pode ser considerado herói no trabalho missionário é o próprio Deus. Tanto a igreja como o missionário são meros cooperadores.

O martírio e o sofrimento acompanham a vida de muitos missionários. Porém é necessário que eles identifiquem e diferenciem os sofrimentos que acontecem por causa do evangelho, daqueles que acontecem por desejos e pensamentos humanos, e assim possam cumprir a sua missão aqui na terra. Devido a um conceito equivocado sobre o sofrimento, onde muitas vezes é considerado com um sinal de fraqueza ou pecado pela comunidade ou líderes religiosos, missionários acabam solitários nos seus sofrimentos. O sofrimento sempre fará parte da vida missionária, porém ele não deve ser suportado ou carregado sozinho. A igreja precisa ser envolvida a cada dia mais com o trabalho do missionário, pois o trabalho missionário é uma ação coletiva entre o missionário e a igreja a serviço de Cristo.

Olhando para o missionário como uma pessoa com emoções e necessidades, o cuidado integral se faz muito necessário. Um cuidado que vai desde a preparação do missionário para o campo, até o seu retorno e aposentadoria. Para que isto aconteça, existe a necessidade do envolvimento de pessoas como pastores, amigos, familiares e profissionais de diversas áreas. Somente desta maneira o cuidado do missionário em sua totalidade pode ser completo. $\mathrm{O}$ seu cuidado integral envolve esse tipo de relacionamento.

A igreja tem um papel fundamental nesse cuidado, pois é dela que saem os missionários para o campo. Ela deveria cuidar do começo ao fim do trabalho do missionário, que vai desde o seu chamado até a sua aposentadoria. O primeiro desafio, para a igreja, é se interessar pela pessoa do missionário e reconhecê-lo como um membro do corpo e não uma máquina que deve demonstrar produção. Depois que existe este interesse pela pessoa, a igreja deveria se envolver em todas as etapas do trabalho missionário, buscando deixá-lo saudável no ministério.

A ajuda para o missionário, em sua grande maioria, provém de ações simples que renovam as forças e trazem consolo em momentos de sofrimento físico e principalmente da alma. Um telefonema, uma carta, um simples "lembrei de você", já fortalecem o missionário por saber que não se encontra sozinho no trabalho. Atitudes de amizade, através das quais o missionário sinta liberdade de ser ele mesmo, sem precisar medir palavras ou esconder sentimentos, são extremamente saudáveis para a saúde emocional. Ali onde se encontra um local seguro para falar das suas alegrias, tristezas, medos e sonhos sem ser julgado, inicia o processo de cura e fortalecimento da sua alma. 


\section{REFERÊNCIAS}

ADIWARDANA, Margaretha. Treinamento formal e não formal anterior ao campo. In: Taylor, William D. (Ed.), Valioso demais para que se perca, um estudo das causas e curas do retorno prematuro de missionários. Londrina: Descoberta, 1998.

BÍBLIA de estudo Almeida. Revista e Atualizada. São Paulo: Sociedade Bíblica do Brasil, 1999.

CHAMPLIN, Russell Norman. O antigo testamento interpretado: versículo por versículo. São Paulo: Candeia, 2000.

COLLINS, Gary R. Aconselhamento Cristão: edição século 21. São Paulo: Vida Nova, 2004.

DONOVAN, Kath; MYORS, Ruth. Reflexões sobre o retorno prematuro de missionários de carreira: uma perspectiva geral do futuro. In: Taylor, William D. (Ed.), Valioso demais para que se perca, um estudo das causas e curas do retorno prematuro de missionários. Londrina: Descoberta, 1998.

ESWINE, Zack. Amizade: remédio de Deus para um ministro esgotado (Parte 1). Ministério Fiel. 2017. Disponível em:

$<$ http://www.ministeriofiel.com.br/artigos/detalhes/1117/Amizade_remedio_de_Deus_para_um_ ministro_esgotado_Parte_1/?utm_source $=$ inf-conteudo\&utm_campaign $=$ inf-

conteudö\&utm_médium=inf-conteudo\&utm_term=inf-conteudo\&utm_content $=$ inf-conteudo $>$. Acesso em: 24/08/2017.

FERNANDO, Ajith. Alegria e sacrifício no Senhor. In: O'Donnell, Kelly (org), Cuidado Integral do Missionário, Perspectivas e práticas ao redor do mundo. Londrina: Descoberta, 2004 .

GIRÓN, Rodolfo. Um modelo integrado de missões. In: Taylor, William D. (Ed.), Valioso demais para que se perca, um estudo das causas e curas do retorno prematuro de missionários. Londrina: Descoberta, 1998.

GORDON-CONWELL RESOURCES. Why do you report such high figures for Christian martyrs? 2015. Disponível em: < http://www.gordonconwell.edu/ockenga/research/Quick-Factsabout-Global-Christianity.cfm\#7>. Acesso em: 19/10/2017.

JOHNSON, Todd M. ZURLO, Gina A. Christian Martyrdom as a Pervasive Phenomenon. In Society. Published online, New York, V. 51, p. 679-685, Dez. 2014. Disponível em: $<$ http://www.gordonconwell.edu/ockenga/research/documents/2Countingmartyrsmethodology.p df $>$. Acesso em: 19/10/2017.

KANG, Sung-Sam. Questões do retorno prematuro: a supervisão. In: Taylor, William D. (Ed.), Valioso demais para que se perca, um estudo das causas e curas do retorno prematuro de missionários. Londrina: Descoberta, 1998.

LEWIS, Jonathan. Investigando as causas e curas da perda de missionários. In: Taylor, William D. (Ed.), Valioso demais para que se perca, um estudo das causas e curas do retorno prematuro de missionários. Londrina: Descoberta, 1998.

LINDQUIST, Brent. Seleção e orientação pela agência missionária: uma experiência pessoal. In: Taylor, William D. (Ed.), Valioso demais para que se perca, um estudo das causas e curas do retorno prematuro de missionários. Londrina: Descoberta, 1998. 
LUNA, Pablo Carrillo. Cuidado pastoral na América Latina: algumas sugestões para as igrejas enviadoras. In: O'Donnell, Kelly (org), Cuidado Integral do Missionário, Perspectivas e práticas ao redor do mundo. Londrina: Descoberta, 2004.

NOTÍCIAS. Você sabe o que é o período sabático? 2008. Disponível em:

$<$ http://www.administradores.com.br/noticias/negocios/voce-sabe-o-que-e-o-periodosabatico/16487/>. Acesso em: 26/10/2017.

O'DONNELL, Kelly. Agindo Globalmente: um modelo para a melhor prática do cuidado missionário. O'DONNELL, Kelly (org). Cuidado Integral do Missionário, Perspectivas e práticas ao redor do mundo. Londrina: Descoberta, 2004.

OLIVEIRA, Roseli M. Kühnrich de. Cuidando de quem cuida. Um olhar de cuidados aos que ministram a Palavra de Deus. 4.ed.Joinville: Grafar, 2012a.

OLIVEIRA, Roseli M. Kühnrich de. Pra não perder a alma. O cuidado aos cuidadores. São Leopoldo: Sinodal, 2012b.

POLLOCK, David. Desenvolvendo o fluxo do cuidado e dos conselheiros. In: O'Donnell, Kelly (org). Cuidado Integral do Missionário - Perspectivas e práticas ao redor do mundo. Londrina: Descoberta, 2004.

STOTT, John. A Bíblia toda, o ano todo. Viçosa: Ultimato, 2007.

TAYLOR, William D. Desafiando os investidores: conclusões e implicações; mais estudos. In: Taylor, William D. (Ed.), Valioso demais para que se perca, um estudo das causas e curas do retorno prematuro de missionários. Londrina: Descoberta, 1998.

TOSTES, Márcia. Preparando para perseverar nas missões brasileiras. In: O'Donnell, Kelly (org). Cuidado Integral do Missionário, Perspectivas e práticas ao redor do mundo. Londrina: Descoberta, 2004.

VAN DER MEER, Antonia Leonora. Missionários feridos, como cuidar dos que servem. Viçosa: Ultimato, 2009.

WIESEMAN, Donald J. 1 e 2Reis: Introdução e comentário. São Paulo: Vida Nova, 2006.

WORLD HEALTH ORGANIZATION. Conceito de Saúde segundo OMS / WHO. 2016.

Disponível em: < http://cemi.com.pt/2016/03/04/conceito-de-saude-segundo-oms-who/>. Acesso em 25/10/2017. 